\title{
Use and self-perceived effects of social media before and after the COVID-19 outbreak: a cross-national study
}

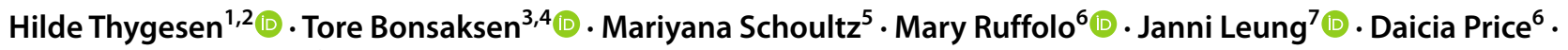 \\ Amy Østertun Geirdal ${ }^{8}{ }^{\circ}$
}

Received: 29 March 2021 / Accepted: 1 September 2021 / Published online: 14 September 2021

(c) The Author(s) 2021

\begin{abstract}
To (i) examine the use of social media before and after the COVID-19 outbreak; (ii) examine the self-perceived impact of social media before and after the outbreak; and (iii) examine whether the self-perceived impacts of social media after the outbreak varied by levels of mental health. A cross-national online survey was conducted in Norway, UK, USA and Australia. Participants $(n=3810)$ reported which social media they used, how frequently they used them before and after the COVID-19 outbreak, and the degree to which they felt social media contributed to a range of outcomes. The participants also completed the 12-item General Health Questionnaire. The data were analyzed by chi-square tests and multiple linear regression analysis. Social media were used more frequently after the pandemic outbreak than compared to before the outbreak. Self-perceived effects from using social media increased after the COVID-19 outbreak, and in particular stress and concern for own and others' health. Emotional distress was associated with being more affected from using social media, in particular in terms of stress and concern for own or others' health. The use of social media has increased during the coronavirus outbreak, as well as its impacts on people. In particular, the participants reported more stress and health concerns attributed to social media use after the COVID-19 outbreak. People with poor mental health appear to be particularly vulnerable to experiencing more stress and concern related to their use of social media.
\end{abstract}

Keywords Coronavirus $\cdot$ COVID- $19 \cdot$ Cross-national study $\cdot$ Emotional distress $\cdot$ Mental health $\cdot$ Social media

\section{Background}

The coronavirus outbreak has caused a global health crisis. The virus, which originated in China, has spread to all continents, causing large numbers of infected and dead worldwide [1]. Due to the highly contagious nature of the virus, the World Health Organization (WHO) recommended a number

This article is part of the COVID-19 Health Technology: Design, Regulation, Management, Assessment

Hilde Thygesen

hilde.thygesen@oslomet.no

1 Faculty of Health Sciences, Department of Occupational Therapy, Prosthetics and Orthotics, Oslo Metropolitan University, Oslo, Norway

2 Faculty of Health Studies, VID Specialized University, Oslo, Norway

3 Faculty of Social and Health Sciences, Department of Health and Nursing Sciences, Inland Norway University of Applied Sciences, Elverum, Norway of measures to prevent further spread [2]. These recommendations include limiting human-to-human transmission by reducing close contacts between people. Following these guidelines, strict rules of social distancing was established in many countries, including Norway, UK, USA and Australia. The social distancing rules implied that people should stay at home and limit any physical contact with others, outside the household, as much as possible. For people infected, or in contact with someone infected by the virus, strict quarantine

4 Faculty of Health Studies, VID Specialized University, Sandnes, Norway

5 Health and Life Sciences, Northumbria University, Newcastle upon Tyne, UK

6 School of Social Work, University of Michigan, Ann Arbor, MI, USA

7 Faculty of Health and Behavioural Science, The University of Queensland, St. Lucia, Australia

8 Faculty of Social Sciences, Department of Social Work, OsloMetropolitan University, Oslo, Norway 
rules applied. The social distancing rules caused nurseries, schools and universities to close, and a lockdown of most of society caused a number of businesses to close, resulting in unemployment rates increasing sharply [3].

Due to complying with the social distancing rules, contact with family outside the household, friends and colleagues were limited to online communication forms, which included the use of social media platforms. Social media are increasingly becoming important platforms of communication and information-exchange [4]. Social media is here understood as "computer-based technology that facilitates the sharing of ideas, thoughts, and information through the building of virtual networks and communities" [5]. In the light of the COVID-19 pandemic, social media played a vital role in connecting people, and in providing updated information about the virus [6].

The COVID-19 outbreak with its strict social distancing measures caused considerable mental health stress in the population [6-9]. This related in part to the many unpredictable aspects of the pandemic, including the growing number of patients and suspected cases across all continents, as well as the obvious concerns about getting infected. Several studies reported increased levels of anxiety and depression related to people being isolated at home, with limited possibilities for face-to-face contact during the corona outbreak [7,9-11]. These studies point to social media as a major contributor to increased levels of stress and mental health problems, arguing that disinformation and false reports have bombarded social media during the COVID-19 outbreak, leading to misinformation overload. In a study of mental health problems and social media exposure during the COVID-19 outbreak in China, for example, the researchers found that persons spending two hours or more a day on social media reported significantly higher levels og mental health problems, and especially anxiety and depression [6]. As such, the role of social media during the corona-outbreak can be understood as ambiguous, as on the one hand it enabled people to stay in touch and be updated on the situation, while at the same time contributing to substantial stress and worry. For example, research has shown that social media may create a sense of community and connectedness [12] and increase one's social capital [13], but also that it may increase symptoms of anxiety and depression [10, 14].

Despite the growing literature on social media, comprehensive comparative studies of social media use, their perceived effects on individuals and their relationship to mental health are scarce. The COVID-19 outbreak constitutes extraordinary circumstances under which whole populations are subject to restrictions and stress. While the use of social media can help to relieve some of that stress by allowing for social contact without physical proximity, negative effects, such as increased worry, are equally viable. Moreover, it is possible that differences in mental health can contribute to determine the perceived impact of social media use. If this is the case, the study may have implications for the approach taken to social media use for different population subgroups.

\section{Study aims}

The aims of this study were to (i) examine the use of social media before and after the COVID-19 outbreak; (ii) examine the self-perceived impact of social media before and after the outbreak; and (iii) examine whether the self-perceived impacts of social media after the outbreak varied by levels of mental health while adjusting by sociodemographic variables.

\section{Methods}

In April 2020, the general population from Norway, USA, UK and Australia was invited to participate in the crosssectional study through a self-administered survey. The online survey was distributed via different social media such as Facebook, Instagram and Twitter. The sampling in each country was done by convenience, implying that all participants opted to participate by self-selection. Each country had a survey landing site at the researcher's universities; OsloMet-Oslo Metropolitan University, Norway; University of Michigan, USA; University of Salford, UK; and the University of Queensland, Australia, respectively. AØG from OsloMet conceptualized and initiated the project. All countries and universities had their own project lead in order to comply with the ethical considerations and permissions of the country and/or institution. Each project lead was able to speak the language of the landing site and English. To ensure that participants were able to understand the survey questions, the survey was presented in Norwegian (to the participants from Norway) and in English (to the participants from USA, UK, an Australia).The data was collected in April and May 2020.

\subsection{Participants}

Participants had to be 18 years or older. They had to understand Norwegian or English and live in Norway, USA, UK or Australia. 


\subsection{Measures}

\subsubsection{Sociodemographic characteristics}

Sociodemographic variables included age group (18-29 years, 30-39 years, 40-49 years, 50-59 years, 60-69 years, 70 years and older), sex (male, female, not stated or other), living area (rural/farming area, small town, medium sized city, large city), highest completed education level (elementary school, high school, associated/technical degree, bachelor's degree, master's degree/doctoral degree), cohabitation (living with someone else or not), and employment status (being in full-time or part-time employment versus being unemployed).

\subsubsection{Social media use}

The participants were asked to indicate whether they had used any of the nine listed well known social media channels before the COVID-19 outbreak. The list was based on US statistics of the most common social media platforms in 2019, and included the following: Facebook, YouTube, Snapchat, Instagram, LinkedIn, Twitter, Pinterest, WhatsApp and Reddit [15]. The participants were then asked how often they had used social media in general (i.e., not for each type of social media) before and after the COVID19 outbreak. Data were collected at one time-point after the COVID-19 outbreak, therefore, "before" was retrospectively recalled by participants. Response options for these items were monthly or less frequently $=1$, weekly $=2$, a few times per week $=3$, daily $=4$, or several times per day $=5$.

The participants were then asked to indicate the selfperceived effects of using social media before and after the COVID-19 outbreak. Listed effects were support, communication, stress, information, being updated, concern for own or others' health, engagement, relaxation, and 'other'. For each of the listed effects, the participants had option to indicate if the use of social media: had no contribution $=1$, contributed a little $=2$, contributed somewhat $=3$, or contributed much $=4$ to the listed effects.

\subsubsection{Mental health}

General Health Questionnaire 12 (GHQ-12) is widely used as a self-reported measure of mental health [16, 17]. A large number of studies in the general adult-, clinical- work and student population have provided support for its validity and reliability across various samples and contexts [17-22]. Six items of the GHQ-12 are phrased positively (e.g. 'able to enjoy dayto-day activities'), while six items are phrased as negative experiences (e.g. 'felt constantly under strain'). On each item, the person indicates the degree to which the item content has been experienced during the two preceding weeks, using four response categories ('less than usual', 'as usual', 'more than usual' or 'much more than usual'). Items are scored between 0 and 3, and positively formulated items are recoded prior to analysis. As a result, the GHQ-12 scale score range is 0-36, with higher scores indicating poorer mental health (more psychological distress). If the person responded 'more than usual' or 'much more than usual' on at least four of the 12 items, this indicates a level of emotional distress where treatment may be needed ('case-level score') [23]. In this study, participants with and without case-level scores were compared with regards to the effects they perceived from using social media.

\subsection{Statistical analysis}

The whole sample, and each of the national subsamples, were described with frequencies and percentages for categorical variables and means and standard deviations for continuous variables. Overall differences in proportions between groups were analyzed with the Chi-Square test, whereas overall group differences in mean scores were analyzed with the $F$-test of the one-way analyses of variance (ANOVA). Differences in self-perceived impact of social media before and after the COVID-19 outbreak were analyzed with the dependent $t$-test.

Associations with self-perceived effects from using social media after the COVID-19 outbreak were investigated with linear regression analysis. Scores on support, communication, stress, information, be updated, concern, engagement and relaxation were used as dependent variables in eight subsequent regression analyses. All analyses included age group, gender, education level, and employment as potential confounders and emotional distress as the independent variable of interest. Effects sizes were reported as standardized beta weights. Statistical significance was set at $p<0.05$. Missing values were managed with casewise deletion, resulting in $n$ varying between analyses. The software used for analysis was SPSS version 26.

\subsection{Ethics}

The data in this cross-sectional and cross-country study were collected anonymously. All ethical rules were followed in each country. The study was quality assured and approved by OsloMet and the regional committees for medical and health research ethics (REK; ref. 132,066) in Norway, reviewed by the University of Michigan Institutional Review Board for Health Sciences and Behavioral Sciences (IRB HSBS) and designated as exempt (HUM00180296) in USA, by University Health Research Ethics (HSR1920-080) in UK, and (HSR1920-080) 2,020,000,956) in Australia. 
Table 1 Sociodemographic characteristics of the total sample and of each of the four subsamples

\begin{tabular}{|c|c|c|c|c|c|c|c|c|c|c|c|}
\hline \multirow[b]{2}{*}{ Characteristics } & \multicolumn{2}{|c|}{$\begin{array}{l}\text { Total } \\
(n=3810)\end{array}$} & \multicolumn{2}{|c|}{$\begin{array}{l}\text { Norway } \\
(n=771, \\
20.2 \%)\end{array}$} & \multicolumn{2}{|c|}{$\begin{array}{l}\text { UK } \\
(n=1373, \\
36.0 \%)\end{array}$} & \multicolumn{2}{|c|}{$\begin{array}{l}\text { USA } \\
(n=1393, \\
36.6 \%)\end{array}$} & \multicolumn{2}{|c|}{$\begin{array}{l}\text { Australia } \\
(n=273, \\
7.2 \%)\end{array}$} & \multirow[b]{2}{*}{$p$} \\
\hline & $n$ & $\%$ & $n$ & $\%$ & $n$ & $\%$ & $n$ & $\%$ & $n$ & $\%$ & \\
\hline \multicolumn{12}{|l|}{ Age group } \\
\hline $18-29$ years & 705 & 18.5 & 188 & 24.4 & 201 & 14.6 & 241 & 17.4 & 75 & 27.5 & \multirow[t]{6}{*}{$<0.001$} \\
\hline 30-39 years & 713 & 18.7 & 176 & 22.8 & 236 & 17.2 & 245 & 17.7 & 56 & 20.5 & \\
\hline 40-49 years & 827 & 21.7 & 198 & 25.7 & 346 & 25.2 & 241 & 17.4 & 42 & 15.4 & \\
\hline 50-59 years & 723 & 19.0 & 116 & 15.0 & 317 & 23.1 & 243 & 17.5 & 47 & 17.2 & \\
\hline 60-69 years & 612 & 16.1 & 71 & 9.2 & 209 & 15.2 & 290 & 20.9 & 42 & 15.4 & \\
\hline 70 years and over & 224 & 5.9 & 22 & 2.9 & 64 & 4.7 & 127 & 9.2 & 11 & 4.0 & \\
\hline \multicolumn{12}{|l|}{ Sex } \\
\hline Male & 718 & 18.8 & 143 & 18.5 & 198 & 14.4 & 324 & 23.3 & 53 & 19.4 & \multirow[t]{3}{*}{$<0.001$} \\
\hline Female & 3034 & 79.6 & 628 & 81.5 & 1159 & 84.4 & 1036 & 74.4 & 211 & 77.3 & \\
\hline Other/not stated & 57 & 1.5 & 0 & 0.0 & 16 & 1.2 & 32 & 2.3 & 9 & 3.3 & \\
\hline \multicolumn{12}{|l|}{ Living area } \\
\hline Rural/farming & 282 & 7.4 & 63 & 8.2 & 76 & 5.5 & 138 & 9.9 & 5 & 1.8 & \multirow[t]{4}{*}{$<0.001$} \\
\hline Small town & 843 & 22.1 & 150 & 19.5 & 233 & 17.0 & 421 & 30.2 & 39 & 14.3 & \\
\hline Medium sized city & 1228 & 32.2 & 116 & 15.0 & 498 & 36.3 & 570 & 40.9 & 44 & 16.1 & \\
\hline Large city & 1457 & 38.2 & 442 & 57.3 & 566 & 41.2 & 264 & 19.0 & 185 & 67.8 & \\
\hline \multicolumn{12}{|l|}{ Education level } \\
\hline Elementary school & 17 & 0.4 & 9 & 1.2 & 0.0 & 0.0 & 3 & 0.2 & 5 & 1.8 & \multirow[t]{5}{*}{$<0.001$} \\
\hline High school & 380 & 10.0 & 112 & 14.5 & 127 & 9.2 & 119 & 8.5 & 22 & 8.1 & \\
\hline Assoc./techn. Degree & 592 & 15.5 & 26 & 3.4 & 331 & 24.1 & 175 & 12.6 & 60 & 22.1 & \\
\hline Bachelor's degree & 1262 & 33.1 & 272 & 35.3 & 462 & 33.6 & 469 & 33.7 & 59 & 21.7 & \\
\hline Master's/PhD degree & 1558 & 40.9 & 352 & 45.7 & 453 & 33.0 & 627 & 45.0 & 126 & 46.3 & \\
\hline \multicolumn{12}{|l|}{ Cohabitation } \\
\hline Yes & 3079 & 80.8 & 610 & 79.1 & 1127 & 82.3 & 1115 & 80.2 & 227 & 83.5 & \multirow[t]{2}{*}{0.19} \\
\hline No & 724 & 19.0 & 161 & 20.9 & 243 & 17.7 & 275 & 19.8 & 45 & 16.5 & \\
\hline \multicolumn{12}{|l|}{ Employment } \\
\hline Yes, full-time & 1890 & 49.6 & 480 & 62.3 & 656 & 47.8 & 644 & 46.3 & 110 & 40.3 & \multirow[t]{3}{*}{$<0.001$} \\
\hline Yes, part-time & 802 & 21.0 & 166 & 21.5 & 309 & 22.5 & 235 & 16.9 & 92 & 33.7 & \\
\hline No & 1117 & 29.3 & 125 & 16.2 & 408 & 29.7 & 513 & 36.9 & 71 & 26.0 & \\
\hline
\end{tabular}

Assoc./techn. degree is associate/technical degree. Statistical tests are Chi-Square tests. Cohabitation refers to 'living with someone else'

\section{Results}

\subsection{Participants}

Characteristics of the sample and the sample subgroups are displayed in Table 1. Differences between countries were statistically significant for all included variables. Among the participants from Norway, $72.9 \%$ were under the age of 50 years, while the corresponding proportions were $57.0 \%$ for the UK, $52.5 \%$ for the USA and $63.4 \%$ for Australia. All countries had a solid majority of female participants (range: $74.4 \%$ in the USA to $84.4 \%$ in the UK). Between $60 \%$ (USA) and $84 \%$ (Australia) reported that they lived in an urban environment (medium-sized or large city). Higher education levels (bachelor level education or higher) were found among $67 \%-81 \%$ of the sample, with the lowest proportion in the UK and the highest proportion in Norway. In all countries, about $80 \%$ lived with others. Full-time employment was reported among $62.3 \%$ of the Norwegian participants, with corresponding proportions ranging $40 \%-48 \%$ in the other countries. Part-time employment was reported among $34 \%$ of the participants from Australia, with corresponding proportions ranging $17 \%-23 \%$ in the other countries. No employment was reported among $37 \%$ of the participants from the USA, with corresponding proportions ranging from 16\%-30\% in Norway, UK and Australia. The respondents reporting no employment were either students, retired, on maternal- or paternal leave or in working age without paid employment. 
Table 2 Use of social media in the total sample and in each of the four countries

\begin{tabular}{|c|c|c|c|c|c|c|c|c|c|c|c|}
\hline \multirow[b]{2}{*}{ Social media } & \multicolumn{2}{|c|}{$\begin{array}{l}\text { Total } \\
(n=3810)\end{array}$} & \multicolumn{2}{|c|}{$\begin{array}{l}\text { Norway } \\
(n=771, \\
20.2 \%)\end{array}$} & \multicolumn{2}{|c|}{$\begin{array}{l}\mathrm{UK} \\
(n=1373, \\
36.0 \%)\end{array}$} & \multicolumn{2}{|c|}{$\begin{array}{l}\text { USA } \\
(n=1393, \\
36.6 \%)\end{array}$} & \multicolumn{2}{|c|}{$\begin{array}{l}\text { Australia } \\
(n=273, \\
7.2 \%)\end{array}$} & \multirow[b]{2}{*}{$p$} \\
\hline & $n$ & $\%$ & $n$ & $\%$ & $n$ & $\%$ & $n$ & $\%$ & $n$ & $\%$ & \\
\hline Facebook $^{\mathrm{a}}$ & 3603 & 94.6 & 741 & 96.1 & 1272 & 92.6 & 1347 & 97.3 & 243 & 89.0 & $<0.001$ \\
\hline YouTube $^{\mathrm{a}}$ & 2652 & 69.6 & 503 & 67.4 & 842 & 61.3 & 1113 & 82.0 & 194 & 71.1 & $<0.001$ \\
\hline Snapchat $^{\mathrm{a}}$ & 1122 & 29.4 & 549 & 73.5 & 236 & 17.2 & 288 & 22.6 & 49 & 17.9 & $<0.001$ \\
\hline Instagram $^{\mathrm{a}}$ & 2121 & 55.7 & 559 & 75.0 & 672 & 48.9 & 733 & 56.1 & 157 & 57.5 & $<0.001$ \\
\hline LinkedIn $^{\mathrm{a}}$ & 1200 & 31.5 & 259 & 35.7 & 293 & 21.3 & 547 & 42.0 & 101 & 37.0 & $<0.001$ \\
\hline Twitter $^{\mathrm{a}}$ & 1194 & 31.3 & 134 & 18.6 & 480 & 35.0 & 496 & 38.1 & 84 & 30.8 & $<0.001$ \\
\hline Pinterest $\mathrm{t}^{\mathrm{a}}$ & 1042 & 27.3 & 172 & 23.8 & 303 & 22.1 & 513 & 39.5 & 54 & 19.8 & $<0.001$ \\
\hline WhatsApp $^{\mathrm{a}}$ & 1643 & 43.1 & 230 & 31.6 & 1072 & 78.1 & 221 & 17.2 & 120 & 44.0 & $<0.001$ \\
\hline \multirow[t]{2}{*}{ Reddit $^{\mathrm{a}}$} & 391 & 10.3 & 41 & 5.8 & 68 & 5.0 & 252 & 19.7 & 30 & 11.0 & $<0.001$ \\
\hline & $M$ & $S D$ & $M$ & $S D$ & $M$ & $S D$ & $M$ & $S D$ & $M$ & $S D$ & $p$ \\
\hline Number of media used ${ }^{b}$ & 4.0 & 1.7 & 4.2 & 1.5 & 3.8 & 1.7 & 4.0 & 1.8 & 3.8 & 1.8 & $<0.001$ \\
\hline
\end{tabular}

${ }^{\text {a }}$ Statistical test is Chi-Square test; ${ }^{\mathrm{b}}$ statistical test is ANOVA $F$-test

\subsection{Use of social media}

The participants' use of various social media in the four countries are displayed in Table 2. In the whole sample, Facebook (94.6\%) YouTube (69.6\%) and WhatsApp (43.1\%) were the most used social media. Facebook was used by a large majority of participants in each of the countries, ranging between $89 \%$ in Australia and $97 \%$ in the USA. The mean number of social media used varied significantly between countries.

The frequency of social media use before and after the COVID-19 outbreak is shown in Table 3. Before the COVID-19 outbreak, the proportion of all participants using social media less frequently than daily was low (ranging between $4.9 \%$ in Norway and $11.7 \%$ in Australia) and further decreased after the COVID-19 outbreak. Similar results were found about daily use. The proportion of participants using social media daily decreased substantially after the COVID-19 (between 6.3\% points in Australia and 12.9\% points in USA). Notably, the proportion of participants using social media several times daily increased substantially for all countries (10.7\% points in Norway, $11.7 \%$ points in Australia, $17.1 \%$ points in the UK and $17.9 \%$ points in the USA).

The frequency of social media use varied systematically by age - while using social media several times per day occurred more often than less frequent social media use in all age groups, the difference was more outspoken in the youngest age groups. Among those aged 18-29 years, 83\% used social media several times daily, while the proportions ranged 53\%-73\% in the other age groups $(p<0.001)$. Participants with higher education were also more inclined to use social media several times daily (73\%), compared to participants with lower levels of education $(69 \%, p<0.05)$.

\subsection{Self-perceived effects of social media use}

Self-perceived effects of the participants' use of social media before and after the COVID-19 outbreak are shown in Table 4. The three most prominent self-perceived effects of social media use were communication, keeping updated and information; these received the highest endorsement before and after the outbreak. This pattern applied to the whole sample and to each of the countries. Relaxation, as a self-perceived effect of social media use, decreased significantly from before to after the outbreak, while all other listed effects increased significantly. The largest effect sizes were found for stress (Cohen's $d=0.59$ ) and concern for own or others' health (Cohen's $d=0.66$ ), for which participants on average reported that social media had contributed to a greater amount of these after the COVID-19 outbreak. This finding was observed in the whole sample and consistently across countries.

\subsection{Associations between emotional distress and self-perceived effects of social media use}

Emotional distress was frequent in all age groups, yet more frequent among participants in the younger age groups. Among those aged 18-29 years, emotional distress was found among 79\%, while ranging between 52 and $70 \%$ in the other age groups $(p<0.001)$. The proportion of participants with emotional distress did not differ by education level (66\% for higher education versus $67 \%$ for lower education, $n s$.).

Table 5 displays associations between emotional distress and self-perceived effects of social media adjusted by sociodemographic variables. The included covariates (age 

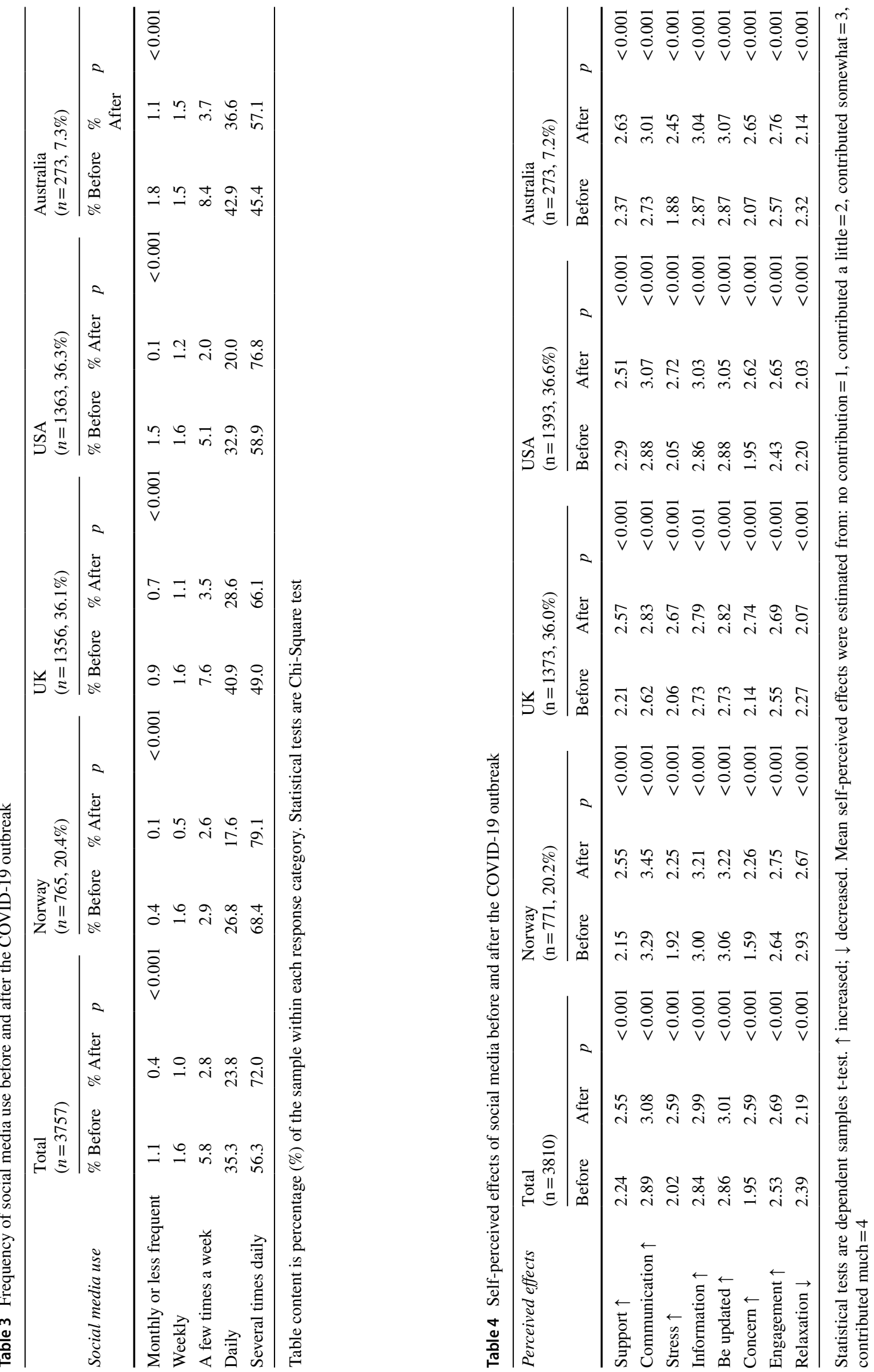
Table 5 Regression analyses showing associations between emotional distress and perceived effects of social media use in the whole sample after the COVID-19 outbreak

\begin{tabular}{|c|c|c|c|c|c|c|c|c|}
\hline & Support & Communication & Stress & Information & Be updated & Concern & Engagement & Relaxation \\
\hline Variables & $\beta$ & $B$ & $\beta$ & $\beta$ & $\beta$ & $\beta$ & $\beta$ & $\beta$ \\
\hline Age group & $-0.08 * * *$ & $-0.18 * * *$ & $-0.18 * * *$ & $-0.12 * * *$ & $-0.13 * * *$ & $-0.08 * * *$ & $-0.04 *$ & $0.04 *$ \\
\hline Sex & $0.12 * * *$ & $0.09 * * *$ & $0.07 * * *$ & $0.05 * *$ & $0.04 * *$ & $0.08 * * *$ & $0.09 * * *$ & 0.01 \\
\hline Education & $0.05 * *$ & $0.10 * * *$ & -0.01 & $0.09 * * *$ & $0.10 * * *$ & $-0.05^{* *}$ & $0.05 * *$ & $0.07 * * *$ \\
\hline Employment & $-0.05 * *$ & $-0.05 * *$ & -0.02 & $-0.05 * *$ & $-0.06 * *$ & -0.02 & -0.02 & -0.03 \\
\hline Emotional distress & $0.05 * *$ & -0.01 & $0.30 * * *$ & 0.02 & $0.04 *$ & $0.22 * * *$ & -0.01 & $-0.16^{* * *}$ \\
\hline Explained variance & $2.7 \% * * *$ & $4.6 \% * * *$ & $15.2 \% * * *$ & $2.4 * * *$ & $2.8 \% * * *$ & $7.3 \% * * *$ & $1.2 \% * * *$ & $3.4 \% * * *$ \\
\hline
\end{tabular}

Variable coding: Lower age group is lower age. Male is 0 , female is 1 . Those reporting sex other than male/female were excluded from the analyses due to insufficient sample size. Higher education group is higher level of education. Having employment is 1 , not having employment is 0 . Emotional distress (indicating that at least four of the GHQ items are rated as indicating more problems than usual) is 1, not emotional distress is 0

${ }^{*} p<0.05 ; * * p<0.01 ; * * * p<0.001$

group, gender, education level and employment status) were significantly associated with most perceived effects from using social media. However, even when adjusting by the sociodemographic covariates, emotional distress was positively associated with perceived support $(\beta=0.05, p<0.01)$, stress $(\beta=0.30, p<0.001)$, be updated $(\beta=0.04, p<0.05)$, concern $(\beta=0.22, p<0.001)$, and negatively associated with relaxation $(\beta=-0.16, p<0.001)$. The regression model explained $15.2 \%$ of the variance in perceived stress, and $7.3 \%$ of the variance in concern. Otherwise, the models had generally low predictive ability, explaining between $1.2 \%$ $4.6 \%$ of the outcome variances.

\section{Discussion}

The aim of this study was threefold: to examine the use of social media before and after the COVID-19 outbreak; to examine the self-perceived impact of social media before and after the outbreak; and to examine whether the selfperceived impacts of social media after the outbreak varied by levels of mental health (emotional distress) while adjusted by sociodemographic variables. The study showed that from the nine listed social media investigated in the study, Facebook was the most frequently used across the four countries, while all other social media were used in different proportions among the participants from the four countries. While there were some differences in the change of use of social media between the countries, the overall change pattern was similar: the participants in all countries used social media more frequently after the pandemic outbreak when compared to before the outbreak. In addition, most of the self-perceived effects from using social media increased after the COVID-19 outbreak, of which stress and concern for own and others' health increased the most. Selfreported emotional distress was significantly associated with a range of self-perceived effects from using social media, most notably stress and concern for own or others' health.

Facebook was used by most participants (89\%-97\%) in all involved countries, and YouTube was also used by well over half $(61 \%-82 \%)$ of the participants. These results correspond well with previous findings concerned with the popularity of various social media worldwide [24]. However, as the survey was distributed via social media channels, the use of various social media may have been more frequent among participants in this study, compared to the general population. In support of this reasoning, a recent survey found that $82 \%$ of the Norwegian general population had a personal profile on Facebook [25], well below the $97 \%$ reporting use of Facebook in this study. Moreover, the use of social media in general may increase rapidly in times of crisis, such as the ongoing COVID-19 pandemic, with increased information as well as misinformation being probable effects [10, 26, 27].

Most of the participants reported a high frequency use of social media, both before and after the COVID-19 outbreak. The biggest change in social media use, when comparing from before to after the pandemic, was the sharp increase in use of social media several times per day (from $56.3 \%$ before the pandemic to $72.0 \%$ after the onset of the pandemic). This finding may be interpreted in view of several factors. In times of crisis there is a need for critical information, which is easily accessed through social media. Also, a crisis - such as the COVID-19 pandemic_-contributes to increased fear and uncertainty in the population [28]. Studies on the use of social media confirm the tendency found in our data, that the frequency of use of social media increases during times of crisis [29-31].

The participants retrospectively reported that the selfperceived effects from using social media were less outspoken before the COVID-19 outbreak, in comparison to after the pandemic. In previous research, social media have 
been shown to contribute to a sense of belonging and connectedness to others [32], and may thereby be an outlet for coping and support [33]. In the context of COVID-19, one study found that social media played an important buffering role by reducing anxiety during a nine-week period in the early stage of the pandemic [34]. In view of models of disaster impact over time [35], it is possible that the connection obtained by social media use may moderate the perceived impact of the crisis in its early stages. However, ways of using social media differ between users, and routine use of social media has been found to have better mental health effects compared to use characterized by emotional connection to the media [36]. The use of social media may also contribute to a way of obtaining information, which is highly relevant in the current situation as information spread via face-to-face communications have been limited due to lockdown and shelter in place policies. This is reflected in our finding that the top reasons for social media use were to keep updated, and for purposes of communication and information. Concerns have been raised that the increasingly vast and fast spread of information that have not gone through a fact-checking process may evoke public panic [26]. Future research on potential psychological distress caused by misinformation on social media may help inform communication strategies to reduce associated negative consequences.

In particular, the study has shown that the negative selfperceived effects of using social media - such as stress and concern for own or other's health - were rated more highly after the onset of the pandemic. This is an unsurprising outcome and - to some extent - may relate to the many uncertainties introduced with the pandemic situation. These uncertainties could range from the worry about the degree of medical severity resulting from oneself or next of kin getting infected by the virus, and thereby possibly causing their deaths, to stress and concerns for the pandemic's impact on daily tasks, work and finances. The timing of our data collection may as such have impacted on these findings. At that time (April and May 2020) the pandemic was in its relatively early stages in the included countries, as were the social distancing regulations and quarantine rules. Also, the global scale of the pandemic and the rapidly rising death tolls at the time of the survey (including the participating countries) may to some extent explain these findings.

Self-reported emotional distress was significantly associated with a range of perceived effects from using social media, most notably stress and concern for own or others' health. Possibly, individuals with poorer mental health may be more attuned towards types of information that evoke stress and concern, as negative information may be more consistent with the more negative worldview frequently held among individuals with poor mental health. This line of reasoning is consistent with research emphasizing attentional bias in persons with mental illness [37, 38]. Individu- als with higher stress levels may also be more inclined to interpret neutral or ambiguous information as threatening. Thus, attentional bias (seeking and noticing fear-consistent information) may be supplemented by an interpretive bias; that is, the tendency to interpret information in consistency with basic fear-driven assumptions. Previous research has found such interpretive bias to contribute to the understanding of individuals suffering from a range of health problems, including social anxiety and alcohol use [39], pain [40] and chronic fatigue [41]. Moreover, more increase in social media-induced stress and concern for own or others' health among those with emotional distress may also reflect their poorer self-efficacy for managing the new demands associated with the changed situation. In support of self-efficacy impacting on stress levels, a previous Swedish study using a general population sample found that men and women with low self-efficacy were more likely to suffer from mental illness, compared to those with higher self-efficacy [42].

We found that those who were not employed were more in agreement that social media contributed to support, communication, information and to being updated. People who were not employed may include people who were no longer working due to COVID-19, people not working due to personal reasons or a disability, or people who have retired and are likely to be older. These sub-populations of our community may be placed at increased risk of vulnerability by the COVID-19 pandemic. Future research into the psychosocial consequences experienced by people who are unemployed during the pandemic is warranted to ensure well-being in this often-neglected sub-population.

\subsection{Study limitations}

Whether, or to what degree, the sample is representative of the population in the four respective countries, in unknown. Representativity can be questioned-for example, the total study sample had a majority of female and urban participants. However, the age and education distributions were well in accordance with general population statistics. Nonetheless, we stress that generalization of the study results to the general population should be done with caution. Access to the internet was required to participate, but the study did not request information about consistent access to internet. Possibly, poorer access to the internet among some groups may have caused these groups to be under-represented in the study.

The study comes with several limitations due to its cross-sectional nature. Our data concerned with social media use before and after the COVID-19 outbreak were collected at the same time-point; asking participants to remember and to state in retrospect how they perceived the impacts of social media before the pandemic outbreak. This strategy makes the responses susceptible to recall and 
response shift biases [43]. As our study was a voluntary survey recruited through social media, we may not have captured samples of populations who may have reduced their social media use. However, due to social distancing measures resulting in populations having a heavier reliance on the use of social media to stay connected, our findings of an increased use of social media is consistent with expectations. Our results may not be used to make causal inferences. Related to this limitation, our large sample size contributed to detecting significant results that showed a small effect size. We have therefore presented the regression coefficients that are standardized, and the proportion of variances explained, to provide better data on the importance of the factors we examined.

\subsection{Conclusion}

Based on the self-reports by the participants in this study, the use of social media appears to have increased during the coronavirus outbreak, as have the impacts social media have on people. In particular, the participants in this study reported more stress and health concerns attributed to social media use after the COVID-19 outbreak, compared to before. People with poor mental health appear to be particularly vulnerable to experiencing more stress and concern related to their use of social media. The study implies that social media may be fruitfully used by health authorities to disseminate relevant information to the public. However, the use of social media after the COVID-19 outbreak was perceived to add to the participants' stress and levels of concern, and particularly so for those reporting emotional distress. Thus, for individuals with emotional distress, social media should be used with critical reflection to maximize their potential for human contact and relevant information, while at the same time minimize their potential for increased stress.

Acknowledgements The authors thank the study participants for their participation.

Author contributions Conceptualization, H.T., T.B., M.S., M.R., D.P ., J.L. and A.Ø.G.; methodology, T.B., H.T., M.S., M.R., D.P., J.L. a nd A.Ø.G.; validation, T.B., H.T., M.S., M.R., D.P., J.L. and A.Ø.G.; formal analysis, H.T. and T.B.; investigation, H.T., T.B., M.S., M.R., D .P., J.L. and A.Ø.G.; data curation, T.B. and A.Ø.G.; writing-original draft preparation, H.T and T.B.; writing — review and editing, H.T., T.B ., M.S., M.R., D.P., J.L. and A.Ø.G.; project administration, A.Ø.G.

Funding Open access funding provided by OsloMet - Oslo Metropolitan University. This research received no specific grant from any funding agency in the public, commercial, or not-for-profit sectors.

Data availability The data from which the conclusions in the current study are based will be available from the corresponding author on reasonable request.
Code availability Not applicable.

\section{Declarations}

Ethics approval The data for this study was collected anonymously. All ethical rules were followed in each country.

Consent to participate Informed consent was obtained from all subjects involved in the study.

Consent for publication All authors have read and agreed to the published version of the manuscript.

Conflict of interest The authors declare that they have no conflict of interest.

Open Access This article is licensed under a Creative Commons Attribution 4.0 International License, which permits use, sharing, adaptation, distribution and reproduction in any medium or format, as long as you give appropriate credit to the original author(s) and the source, provide a link to the Creative Commons licence, and indicate if changes were made. The images or other third party material in this article are included in the article's Creative Commons licence, unless indicated otherwise in a credit line to the material. If material is not included in the article's Creative Commons licence and your intended use is not permitted by statutory regulation or exceeds the permitted use, you will need to obtain permission directly from the copyright holder. To view a copy of this licence, visit http://creativecommons.org/licenses/by/4.0/.

\section{References}

1. World Health Organization. WHO Coronavirus Disease (COVID19) Dashboard. Availabe online: https://covid19. who.int/ (Accessed on June 24, 2020).

2. World Health Organization. Coronavirus disease (COVID-19) advice for the public. Availabe online: https://www.who.int/ emergencies/diseases/novel-coronavirus-2019/advice-for-public (Accessed on 24 June, 2020).

3. Blustein DL, Duffy R, Ferreira JA, Cohen-Scali V, Cinamon RG, Allan BA. Unemployment in the time of COVID-19: A research agenda. J Vocat Behav. 2020. https://doi.org/10.1016/j.jvb.2020. 103436.

4. Kontos EZ, Emmons KM, Puleo E, Viswanath K. Communication inequalities and public health implications of adult social networking site use in the United States. J Health Commun. 2010;15(Suppl 3):216-35. https://doi.org/10.1080/10810730. 2010.522689.

5. Dollarhide, M. Social media. Availabe online: https://www.investopedia. $\mathrm{com} /$ terms/s/social-media.asp (Accessed on 20 July 2020).

6. Bao Y, Sun Y, Meng S, Shi J, Lu L. 2019-nCoV epidemic: address mental health care to empower society. The Lancet. 2020;395:e37-8. https://doi.org/10.1016/S0140-6736(20) 30309-3.

7. Ni, MY. Yang L. Leung CMC, Li N, Xi, Y, Wang Y, Leung GM, Cowling BJ, Liao Q. Mental Health, Risk Factors, and Social Media Use During the COVID-19 Epidemic and Cordon Sanitaire Among the Community and Health Professionals in Wuhan, China: Cross-Sectional Survey. JMIR Ment Health 2020; 7:e19009. https://doi.org/10.2196/19009.

8. Roy D, Tripathy S, Kar SK, Sharma N, Verma SK, Kaushal V. Study of knowledge, attitude, anxiety \& perceived mental healthcare need in Indian population during COVID-19 pandemic. 
Asian J Psychiatr. 2020;51: 102083. https://doi.org/10.1016/j. ajp.2020.102083.

9. Li W, Yang Y, Liu ZH, Zhao YJ, Zhang Q, Zhang L, Cheung T, Xiang YT. Progression of Mental Health Services during the COVID-19 Outbreak in China. Int J Bioogicall Sci. 2020;16:1732-8. https://doi.org/10.7150/ijbs.45120.

10. Gao J, Zheng P, Jia Y, Chen H, Mao Y, Chen S, Wang Y, Fu H, Dai J. Mental health problems and social media exposure during COVID-19 outbreak. PLoS One. 2020;15.

11. Cheng P, Xia G, Pang P, Wu B, Jiang W, Li YT, Wang M, Ling Q, Chang X, Wang J, et al. COVID-19 Epidemic Peer Support and Crisis Intervention Via Social Media. Community Ment Health J. 2020;56:786-92. https://doi.org/10.1007/s10597-020-00624-5.

12. Gibson K, Trnka S. Young people's priorities for support on social media: "It takes trust to talk about these issues." Comput Hum Behav. 2020;102:238-47. https://doi.org/10.1016/j.chb.2019.08. 030.

13. Rykov Y, Koltsova O, Sinyavskaya Y. Effects of user behaviors on accumulation of social capital in an online social network. PLoS One. 2020;15.

14. Sujarwoto S, Tampubolon G, Pierewan AC. A Tool to Help or Harm? Online Social Media Use and Adult Mental Health in Indonesia. Int J Ment Heal Addict. 2019;17:1076-93. https://doi.org/ 10.1007/s11469-019-00069-2.

15. Perrin A, Anderson M. Share of US adults using social media, including Facebook, is mostly unchanged since 2018. Availabe online: https://www.pewresearch.org/fact-tank/2019/04/10/shareof-u-s-adults-using-social-media-including-facebook-is-mostlyunchanged-since-2018/ (Accessed on March 25th 2021).

16. Goldberg DP, Gater R, Sartorius N, Ustun TB, Piccinelli M, Gureje $\mathrm{O}$, Rutter $\mathrm{C}$. The validity of two versions of the GHQ in the WHO study of mental illness in general health care. Psychol Med. 1997;27:191-7. https://doi.org/10.1017/s0033291796004242.

17. Goodwin L, Ben-Zion I, Fear NT, Hotopf M, Stansfeld SA, Wessely S. Are reports of psychological stress higher in occupational studies? A systematic review across occupational and population based studies. PLoS One. 2013;8.

18. Adlaf EM, Gliksman L, Demers A, Newton-Taylor B. The prevalence of elevated psychological distress among Canadian undergraduates: findings from the 1998 Canadian Campus Survey. J Am Coll Health. 2001;50:67-72. https://doi.org/10.1080/07448480109596009.

19. Firth J. Levels and sources of stress in medical students. BMJ. 1986;292:1177-80. https://doi.org/10.1136/bmj.292.6529.1177.

20. Gorter R, Freeman R, Hammen S, Murtomaa H, Blinkhorn A, Humphris G. Psychological stress and health in undergraduate dental students: fifth year outcomes compared with first year baseline results from five European dental schools. Eur J Dent Educ. 2008;12:61-8. https://doi.org/10.1111/j.1600-0579.2008.00468.x.

21. Aalto A-M, Elovainio M, Kivimäki M, Uutela A, Pirkola S. The Beck Depression Inventory and General Health Questionnaire as measures of depression in the general population: a validation study using the Composite International Diagnostic Interview as the gold standard. Psychiatry Res. 2012;197:163-71. https://doi. org/10.1016/j.psychres.2011.09.008.

22. Geirdal AØ, Ruffolo M, Leung J, Thygesen H, Price D, Bonsaksen T, Schoultz M. Mental health, quality of life, wellbeing, loneliness and use of social media in a time of social distancing during the COVID-19 outbreak. A cross country comparative study. J Mental Health 2021. https://doi.org/10.1080/09638237.2021.1875413.

23. Goldberg DP, Oldehinkel T, Ormel J. Why GHQ threshold varies from one place to another. Psychol Med. 1998;28:915-21.

24. Statista. Most popular social networks worldwide as of April 2020, ranked by number of active users. Availabe online: https:// www.statista.com/statistics/272014/global-social-networksranked-by-number-of-users/ (Accessed on 24 June, 2020).
25. Hide YO. Ny statistikk for bruk av sosiale medier i Norge. Availabe online: https://racer.no/blogg/ny-statistikk-for-bruk-av-sosialemedier-i-norge (Accessed on 24 June, 2020).

26. Depoux A, Martin S, Karafillakis E, Preet R, Wilder-Smith A, Larson $\mathrm{H}$. The pandemic of social media panic travels faster than the COVID-19 outbreak. J Travel Med. 2020; 27. https://doi.org/ 10.1093/jtm/taaa031.

27. Chan AKM, Nickson CP, Rudolph JW, Lee A, Joynt GM. Social media for rapid knowledge dissemination: early experience from the COVID-19 pandemic. Anaesthesia. 2020. https://doi.org/10. 1111/anae.15057.

28. Satici B, Saricali M, Satici SA, Griffiths MD. Intolerance of Uncertainty and Mental Wellbeing: Serial Mediation by Rumination and Fear of COVID-19. Int J Ment Heal Addict. 2020. https:// doi.org/10.1007/s11469-020-00305-0.

29. Austin L, Fisher Liu B, Jin Y. How Audiences Seek Out Crisis Information: Exploring the Social-Mediated Crisis Communication Model. J Appl Commun Res. 2012;40:188-207. https://doi. org/10.1080/00909882.2012.654498.

30. Graham MW, Avery EJ, Park S. The role of social media in local government crisis communications. Pub Relations Rev. 2015;41:386-94. https://doi.org/10.1016/j.pubrev.2015.02.001.

31. Cho SE, Jung K, Park HW. Social Media Use during Japan's 2011 Earthquake: How Twitter Transforms the Locus of Crisis Communication. Media International Australia. 2013;149:28-40. https:// doi.org/10.1177/1329878X1314900105.

32. Allen KA, Ryan T, Gray DL, McInerney DM, Waters L. Social Media Use and Social Connectedness in Adolescents: The Positives and the Potential Pitfalls. Au Educ Dev Psychol. 2014;31:18 31. https://doi.org/10.1017/edp.2014.2.

33. Naslund JA, Aschbrenner KA, Marsch LA, Bartels SJ. The future of mental health care: peer-to-peer support and social media. Epidemiol Psychiatric Sci. 2016;25:113-22. https://doi.org/10.1017/ s2045796015001067.

34. Marzouki Y, Aldossari FS, Veltri GA. Understanding the buffering effect of social media use on anxiety during the COVID-19 pandemic lockdown. Humanit Soc Sci Commun. 2021;8:47. https:// doi.org/10.1057/s41599-021-00724-x.

35. Everly GS, Wu AW, Potash JB. Phases of psychological response in COVID-19: A preliminary heuristic. Am J Disaster Med. 2021;16:5-12. https://doi.org/10.5055/ajdm.2021.0381.

36. Bekalu MA, McCloud RF, Viswanath K. Association of social media use with social well-being, positive mental health, and selfrated health: disentangling routine use from emotional connection to use. Health Educ Behav. 2019;46:69S-80S. https://doi.org/10. $1177 / 1090198119863768$.

37. Zvielli A, Vrijsen JN, Koster EH, Bernstein A. Attentional bias temporal dynamics in remitted depression. J Abnorm Psychol. 2016;125:768-76. https://doi.org/10.1037/abn0000190.

38. Lazarov A, Ben-Zion Z, Shamai D, Pine DS, Bar-Haim Y. Free viewing of sad and happy faces in depression: A potential target for attention bias modification. J Affect Disord. 2018;238:94-100. https://doi.org/10.1016/j.jad.2018.05.047.

39. Chow PI, Portnow S, Zhang D, Salemink E, Wiers RW, Teachman BA. Comorbid interpretation and expectancy bias in social anxiety and alcohol use. Anxiety Stress Coping. 2018;31:669-85. https:// doi.org/10.1080/10615806.2018.1521958.

40. Heathcote LC, Koopmans M, Eccleston C, Fox E, Jacobs K, Wilkinson N, Lau JY. Negative Interpretation Bias and the Experience of Pain in Adolescents. Journal of Pain. 2016;17:972-81. https://doi.org/10.1016/j.jpain.2016.05.009.

41. Hughes A, Hirsch C, Chalder T, Moss-Morris R. Attentional and interpretive bias towards illness-related information in chronic fatigue syndrome: A systematic review. Br J Health Psychol. 2016;21:741-63. https://doi.org/10.1111/bjhp.12207. 
42. Andersson LMC, Moore CD, Hensing G, Krantz G, StalandNyman C. General Self-efficacy and Its Relationship to Selfreported Mental Illness and Barriers to Care: A General Population Study. Community Ment Health J. 2014;50:721-8. https:// doi.org/10.1007/s10597-014-9722-y.

43. Rosenman R, Tennekoon V, Hill LG. Measuring bias in selfreported data. Int J Behav Healthc Res. 2011;2:320-32. https:// doi.org/10.1504/IJBHR.2011.043414.
Publisher's Note Springer Nature remains neutral with regard to jurisdictional claims in published maps and institutional affiliations. 